\title{
A Review on the Removal of Fluoride using Inexpensive Adsorbents
}

\author{
Radha $\mathrm{N}^{1}$ \\ ${ }^{1}$ Assistant Professor, \\ Mount Zion College of Engineering and Technology, \\ Pudukkottai
}

\author{
Dr. Bhagavathi Pushpa $T^{2}$ \\ ${ }^{2}$ Assistant Professor, \\ Anna University, University College of Engineering, \\ Ramanathapuram
}

\begin{abstract}
Due to the weathering of rocks, effluents from industries and geochemical responses the fluoride interacts with the ground water. Precipitation, adsorption, ion-exchange, membrane process techniques helps to process defluoridation in water. Among these fluoride removal strategies, adsorption technique is direct, reasonable, and appropriate for drinking water treatment. A few adsorbents, for example, activated carbon and alumina, agricultural and industrial wastes etc., were endeavor the permissible range of fluoride availability in water by adsorption technique. Use of plant related materials and agricultural wastes as adsorbents are commonly involved in adsorption technique since these materials are easily available with biodegradable nature and also they are inexpensive materials. The principle reason for this literature survey is to give new thoughts regarding the defluoridation in aqueous solutions by adsorption method which was analyzed by numerous analysts. In this review paper, different adsorbents has been reviewed and their adsorption efficiency based on $\mathrm{pH}$, initial fluoride concentration, temperature, contact time has been analysed. It is obvious from the review that the various adsorbents have demonstrated incredible capability of defluoridation. Be that as it may, at present there is an earnest requirement for the identification and improvement of progressively novel adsorbents which depends on economic and innovative aspects.
\end{abstract}

\section{Keywords: Defluoridation, adsorption, adsorbent}

\section{INTRODUCTION}

Water is the most important and essential requirement in day to day regular life. In numerous parts of the world, fluoride contaminated drinking water is perceived as a significant public health issue. Presence of fluoride in groundwater is the most harmful constituent which signifies a potential hazard to human wellbeing. Dependent upon the measure of fluoride ingested or its fixation in drinking water, it is considered as a fundamental constituent for both humans and animals. As per World Health Organization (WHO) and IS: 10500 , the proposed limit of fluoride in drinking water ought to be 1.0 to $1.5 \mathrm{ppm}$. Fluoride is routinely called a twoedged sword which has both ruinous impact and valuable impact. If the fluoride concentration in water is within reasonable points of confinement of $0.5-1.0 \mathrm{mg} / \mathrm{l}$, it will be useful for the creation and upkeep of teeth and healthy bones, while the fluoride content exceeds $1.5 \mathrm{ppm}$ causes dental and skeletal fluorosis. Fluoride in abundance causes wellbeing dangers to the regular habitat. Thus awareness on fluoride removal, utilizing best technique with most extreme efficiency is required. Among different systems practiced in water defluoridation, adsorption strategy possesses a conspicuous spot in fluoride removal, as this technique is so basic and affordable. Use of plant related materials and agricultural waste products as adsorbents are highly embraced that those materials are accessible in abundance, ease materials, biodegradable and regular in presence. As cost is likewise a significant thought, endeavors investigated the possibility of utilizing different inexpensive adsorbents that are plentiful, promptly accessible and are obtained from waste materials. This literature survey overviews that different adsorbents and their adsorption limits which have great potential for the fluoride removal from amphibian conditions and furthermore evaluates the reasonableness of low cost adsorbents to viably remediate fluoride-polluted water. Taking the seriousness of the impacts of fluoride into thought, the present paper surveys the viable and modest adsorbents for the defluoridation in water.

\section{DEFLUORIDATION METHODS}

Defluoridation is the descending change of fluoride level in water to the ideal level. The different strategies executed for fluoride removal are precipitation, ion-exchange, membrane process and technique. Precipitation is the entrenched and generally utilized strategy, especially at the community level. In any case, it has just moderate effectiveness and a high chemical dose is required. Inordinate utilization of aluminum salts produces sludge and unfavorable wellbeing impacts through aluminum solubility. Ion exchange removes fluoride up to $90-95 \%$ and holds the taste and colour of the water. Moderately significant expense is the inconvenience and treated water has a low $\mathrm{pH}$ value and high levels of chloride. This technique requires standard substitution of resin and huge measure of salts are associated with regeneration. Membrane process is successful procedure and doesn't require chemicals. This works at wide $\mathrm{pH}$ range and obstruction by other ions is negligible. This technique requires greater expenses and skilled labour and isn't suitable for water with high salinity. Adsorption process is the adsorption of fluoride particles onto the surface of an active agent. Adsorption can be accomplished with locally accessible adsorbent materials with high efficiency and it is a cost-effective method.

\section{LITERATURE REVIEW}

Parlikar et al. (2015) considered the removal of fluoride utilizing tea waste and drumstick as bioadsorbants. For neutral $\mathrm{pH}$ for fluoride ion removal, the acid treated tea ash powder was better than alkali treated tea ash powder. But for Moringa Oleifera, the alkali treated MO powder was found better than acid treated $\mathrm{MO}$ powder at neutral $\mathrm{pH}$. As the $\mathrm{pH}$ value increases, the removal of fluoride by adsorption 
increases for both bioadsorbents and adsorption is maximum at neutral $\mathrm{pH}$. For both bioadsorbents, the removal efficiency by adsorption was seen as optimum at adsorbent dose of $400 \mathrm{mg} / \mathrm{lit}$ and the contact time was $150 \mathrm{mins}$ for $212 \mu$ and $600 \mu$. The author observed that the rate of adsorption is more for small particle size $(212 \mu)$ of bioadsorbent because of increase in surface area than large particle size $(600 \mu)$. [1]

Ramesh et al. (2012) researched the batch and column process for the defluoridation of aqueous solution utilizing bottom ash. The contact time of fluoride was identified as 105 minutes at $70 \mathrm{mg} / 100 \mathrm{ml}$ bottom ash dosage with the maximum efficiency of $73.5 \%$. For the adsorption efficiency of $83.2 \%$, the $\mathrm{pH}$ was 6 . Likewise the fluoride removal tends to increase with a decrease in the molecule size. The most extreme monolayer adsorption limit of bottom ash adsorbent was identified as $16.26 \mathrm{mg} / \mathrm{g}$ at $303 \mathrm{~K}$. From the column process, it was identified that the fluoride ions increase tends to increase in the bed height, because of an increase with the contact time. From the Thomas model, the author observed that the rate constant is $0.0619 \mathrm{l} / \mathrm{min} . \mathrm{mg}$ and the adsorption limit was observed as $0.3714 \mathrm{mg} / \mathrm{g}$.. From the Yoon Nelson model it was seen that $50 \%$ of adsorbate at time of 2140 minutes runs at the rate constant of $0.0031 / \mathrm{min}$ [2]

Saranya et al (2016) researched the defluoridation utilizing bio adsorbents, for example, banana peel, passion fruit peel and passion fruit seed. More prominent removal effectiveness was achieved by utilizing banana peel powder. The authors concluded that the efficiency of fluoride removal increases with increase in adsorbent dose. [3]

Aleena et al. (2016) examined the defluoridation of water by utilizing moringa oleifera and thulsi. The authors observed that the removal of fluoride increases with an increase in the adsorbent dose. The quantity of adsorbent dose was ranged from $0.1 \mathrm{mg} / \mathrm{lit}$ to $0.5 \mathrm{mg} / \mathrm{lit}$ in aqueous solutions. The authors also came to know that for Moringa Oleifera bioadsorbent, the maximum removal efficiency of fluoride was $40 \%$ at 0.5 $\mathrm{mg} / \mathrm{lit}$ while fluoride removal efficiency was $23 \%$ at 0.5 $\mathrm{mg} / \mathrm{lit}$ by utilizing Thulsi as adsorbent. Subsequently the authors reasoned that the utilization of the moringa oleifera seed powder and thulsi leaves as bio adsorbent for fluoride removal is attainable and furthermore the moringa oleifera seed powder was superior to thulsi leaves for defluoridation. [4]

Sutapa Chakrabarty et al. (2012) examined the fluoride removal of drinking water utilizing neem stem as an adsorbent. The neem stem charcoal is seen as an effective adsorbent for the defluoridation of drinking water source. The adsorbent was effective with $94 \%$ efficiency in removal of fluoride particles from aqueous solution of $10 \mathrm{mg} / \mathrm{l}$ fluoride concentration. Biosorption equilibrium was accomplished within 180 minutes. The authors found that the adsorption was $\mathrm{pH}$ dependent and the most extreme adsorption accomplished at $\mathrm{pH}$ of 5.0. [5]

Bina Rani et al. (2012) examined the defluoridation of water utilizing brick powder as an adsorbent. Adsorbent efficiency of brick powder was observed for the fluoride removal from potable water samples of different concentrations. The author inferred that the adsorption of fluoride on brick powder adsorbent from aqueous solution was considered as first order reaction and the mechanism of the removal of fluoride on adsorbent was found to be complex. Presence of other ions in groundwater didn't influence the defluoridation procedure, in this way, showing that the brick powder is an appropriate and economical adsorbent for fluoride. [6]

Renu singh et al. (2008) investigated the fluoride removal in potable water utilizing brick powder as an adsorbent. The impact of adsorbent dosage on adsorption of fluoride was examined at $\mathrm{pH}$ value of 8 for a contact time of $60 \mathrm{~min}$. The removal of fluoride was increased from $43.2 \%$ to $56.8 \%$ for 0.2 to $2.0 \mathrm{~g} / 100 \mathrm{ml}$ dosage of brick powder. [7]

Vinish V Nair et al. (2016) examined the fluoride removal by composite bed of inexpensive bio-adsorbents. The authors found that the moringa oleifera adsorbent at contact time of 30 minutes shows the fluoride removal by $98.1 \%$ efficiency. Anyway the turbidity of treated water is seen as exceptionally high. Column experimentation was likewise led for various composite beds of bio-adsorbents. At a contact time of 30 minutes, a composite bed of $4 \mathrm{~cm}$ thick was designed. This composite bed comprising of $75 \%$ rice husk activated charcoal and $25 \%$ moringa oleifera is seen as fundamentally decreases the turbidity together with $90 \%$ fluoride removal from water. [8]

G.R.Kiran Kumar et al. (2016) researched the defluoridation of water by utilizing low cost activated carbon obtained from lemon peels. Investigations were made for various adsorption parameters, for example, $\mathrm{pH}$, adsorbent dose, contact time, agitation speed which results that the lemon peels activated carbon could be utilized for fluoride removal from water. The authors concluded that fluoride adsorption was higher in the $\mathrm{pH}$ of 4 and further increase in $\mathrm{pH}$ brought about decrease of adsorption rate. Maximum removal of fluoride efficiency was achieved at a contact time of $120 \mathrm{~min}$ with adsorbent dose of $10 \mathrm{~g} / \mathrm{l}$ at an agitation speed of $225 \mathrm{rpm}$. [9]

Satyanarayana et al. (2015) examined the fluoride removal utilizing brick powder as an adsorbent. The author found that as contact time increases, ppm removal likewise increases initially and diminishes continuously with time and achieves very nearly a balance condition in almost 72 hours and stays constant from there on. A limit of 85 percent removal could be practiced by brick powder. Equilibrium isothermal sorption tests proposed that the sorbent dosages of $9 \mathrm{~g} / \mathrm{l}$ of brick powder achieved fluoride removal of $85 \%$ and the contact time was 72 hours. $\mathrm{pH}$ doesn't have any critical effect in the range of 2 to 10 , though $\mathrm{pH}$ beyond 10 brought about a gradual decrease in defluoridation. [10]

Nikhil Chavan et al. [2013] examined the fluoride removal from water utilizing inexpensive adsorbents, for example, beetroot seeds and okra seeds. A limit of $87 \%$ and $83 \%$ t removal is obtained by utilizing beetroot seeds and okra seeds at an optimum contact time of 90 minutes. At a portion of 8 $\mathrm{gm} / \mathrm{lit}$, the measure of fluoride adsorbed was seen as 
optimum. Maximum removal efficiency was accomplished at $\mathrm{pH}$ of 7 for both the adsorbents. The effectiveness of maximum fluoride removal for both adsorbents is seen as good at $150 \mathrm{rpm}$. Column experiments gave efficiency in initial stage as 78 percent yet the effectiveness continues diminishing. [11]

N. Gandhi et al. (2012) researched the fluoride removal efficiency using inexpensive adsorbents in water and waste water. The author chose chalk powder, ragi seed powder, horse gram seed powder, pine apple peel powder, orange peel powder, red soil, multhani matti as adsorbents for the defluoridation. The adsorption limit is more at lower concentrations contrasted with higher concentration. The author found that the order based on adsorption capacity is chalk powder, pine apple strip powder, orange strip powder, horse gram seed powder, red soil, ragi seed powder and multhani mati. [12]

Ranjeeta Soni et al. (2013) examined the fluoride removal from drinking water utilizing red mud. According to the experimental outcomes, the author inferred that the red mud can change the fluoride concentration acceptable as indicated by as far as possible $1.15 \mathrm{mg} / \mathrm{l}$ just as like different adsorbents. The raw material likewise effectively accessible and after the defluoridation from red mud the impacts on water quality will not disturbed as on account of chemical adsorbents since it is a natural adsorbent [13]

Bhaumik et al. (2012) examined the eggshell powder for the defluoridation process. The most extreme adsorption happened at $\mathrm{pH}$ of 2.0 to 6.0. Experimental equilibrium data furnished the best fit with the Langmuir isotherm model, showing monolayer sorption on a homogenous surface. Thermodynamic investigation proposes that the fluoride removal from aqueous solution by eggshell powder as an adsorbent was an unconstrained and exothermic procedure. [14]

Gourouza et al. (2014) investigated the defluoridation process using charred beef shoulder blade bones. The outcome of adsorption shows that the beef calcined bone is an antecedent material, proper for the defluoridation of aqueous solutions. It was discovered that the mass of fluoride adsorbed on the adsorbent relies upon the adsorbent dose, the initial fluoride concentration and the contact time. [15]

Shrotri et al. (2017) examined the defluoridation of water by utilizing brick powder (BP) and alum impregnated on brick powder (AIBP). The author talked about the inexpensive adsorbents which are advantageously utilized for defluoridation locally. Bricks and alum is extremely economical material for adsorbent preparation and it is locally accessible. Subsequently the author inferred that the bricks and alum is conceivably great adsorbent of fluoride. The adsorption limit of alum impregnated bricks powder is higher than bricks powder. [16]

Priya Goswami et al. (2015) examined the defluoridation of water utilizing leaf powder from neem (Azadirachtaindica) trees. The adsorption limit of treated biosorbents was considered by altering the particle size. With the biggest particle size of $1.4 \mathrm{~mm}$, the measure of fluoride particles adsorbed was seen as $50 \%$. With littlest molecule size of $600 \mu$ for an initial fluoride ion concentration of $10 \mathrm{mg} / \mathrm{l}$, the efficiency of adsorption is $90 \%$. The level of fluoride removal was seen as a component of adsorbent particle size and time at a given initial solute concentration. [17]

Chakrapani et al. (2010) considered the removal of fluoride from aqueous solution by activated carbon adsorbents obtained from the peels of chosen citrus fruits. Activated carbons were prepared from the peels of citrus documana, citrus medica and citrus aurantifolia fruits. The examination on adsorption of fluoride on these activated carbons was examined. Impact of contact time in the fluoride removal from aqueous solution at neutral $\mathrm{pH}$ was explored. Five kinetic models; the pseudo first order and second order conditions, intraparticle dissemination, pore diffusion and the Elovich condition, were chosen to pursue adsorption process. [18]

Patil Satish et al. (2013) examined the defluoridation of water utilizing biosorbents. The author explored the efficiency of mangrove plant leaf powder (MPLP), chiku leaf powder (CLP), almond tree bark powder (ATBP), toor plant leaf powder (TPLP), pineapple peel powder (PPP), and coconut coir pith (CCP). The authors examined about the impact of $\mathrm{pH}$, contact time, temperature, adsorbent dose, adsorbent size, agitation speed and fluoride ion concentration on removal efficiency of fluoride. The adsorption kinetics has been found to pursue first order rate mechanism for pineapple peel powder and almond tree bark powder yet different adsorbents pursued second order rate mechanism. The examined adsorbents fulfilled Temkin, Freundlich, Langmuir isotherm models. [19]

Aashmohammad et al. (2014) researched about the defluoridation in synthetic water by utilizing banana peel, groundnut shell and sweet lemon peel. The sweet lemon peel, banana peel and groundnut shell expelled $94.34 \%$,

$89.95 \%$ and $59.59 \%$ separately from an aqueous solution of $20 \mathrm{mg} / \mathrm{l}$ fluoride at $\mathrm{pH}$ of $6.0,7.0$ and 4.0 individually. Contact time for banana peel, groundnut shell, and sweet lemon peel was $60 \mathrm{~min}, 75 \mathrm{~min}$ and $40 \mathrm{~min}$ and dose $14 \mathrm{gm} / \mathrm{l}$, $12 \mathrm{gm} / 1$ and $16 \mathrm{gm} / 1$ individually. [20]

Dwivedi Shubha et al. (2014) considered the removal of fluoride utilizing citrus limetta. The impact of time and initial concentration of fluoride on the removal percentage was studied. Kinetics parameters and equilibrium constants are listed from the different kinetic and equilibrium models. Fluoride adsorption on the citrus limetta fulfilled with the pseudo second order rate equation. The equilibrium data were found to fit well with Freundlich isotherm for the chosen adsorbent. [21]

Harikumar et al. (2012) researched the defluoridation of water utilizing biosorbents, for example, vetiver root, tamarind seed and clove. Among every one of those biosorbents the author reasoned that the vetiver root was seen as empowering for the 
fluoride removal. In its activated powdered structure, vetiver root can possibly be an effective defluoridating adsorbent in correlation with different adsorbents. The equilibrium data got fitted well with Langmuir and Freundlich isotherms. SEM micrographs of activated vetiver adsorbent after fluoride stacking affirmed the adsorption of fluoride. [22]

Sudarshan et al. (2014) investigated the adequacy of tulsi for fluoride removal in groundwater. The author detected that on treating the groundwater samples containing high fluoride concentration with tulsi leaves there is a slight or no adjustment in fluoride level. In a similar way even tulsi paste and panch tulsi liquid were having unimportant impact on the concentration of fluoride particles in groundwater. The fluoride concentration in groundwater samples having high qualities i.e $7 \mathrm{mg} / \mathrm{l}$ and $5 \mathrm{mg} / \mathrm{l}$ was diminishing by 1 or $2 \mathrm{mg} / \mathrm{l}$ and following a few hours the concentration was increasing again and attaining the levels of fluoride as in raw water. The author presumed that there is no obvious decline in fluoride concentration in the water samples on treating it with tulsi leaves.[23]

Chakrabarty et al. (2012) examined the defluoridation of polluted drinking water utilizing neem charcoal adsorbent. This adsorbent is recognized as an efficient adsorbent for the defluoridation of water sources. The biosorbent was effective in the fluoride particles removal of $10 \mathrm{mg} / \mathrm{l}$ fluoride concentration from aqueous solution with $94 \%$ efficiency. Biosorption equilibrium was attained within 180 minutes. The author witnessed that the adsorption efficiency depends on $\mathrm{pH}$ with maximum adsorption attained at $\mathrm{pH}$ of 5.0. [24]

Dwivedi et al. (2014) examined the adsorption capacity of ficusreligiosa (peepal leaf powder) for fluoride removal. The author presumed that the ideal $\mathrm{pH}$ for the fluoride removal by the examined adsorbents is 7 and the optimum adsorbent dose for the researched adsorbent is $10 \mathrm{~g} / \mathrm{l}$ for the elimination of fluoride from water. The optimum temperature for fluoride removal is $30^{\circ} \mathrm{C}$. The adsorbent dose tends to increase from $0.09 \mathrm{mg} / \mathrm{g}$ to $1.48 \mathrm{mg} / \mathrm{g}$ with an increase in initial fluoride concentration from $1 \mathrm{mg} / \mathrm{l}$ to $20 \mathrm{mg} / \mathrm{l}$. For the initial fluoride concentration of $5 \mathrm{mg} / \mathrm{l}$, the efficiency of fluoride removal of peepal leaf powder adsorbent is $85.7 \%$ [25]

Mekala suneetha et al. (2015) examined the removal of fluoride from contaminated water utilizing active carbon got from barks of vitex negundo plant. Nitric acid activated carbon got from the vitex negundo plant barks was seen as a effective adsorbent for the de-fluoridation of water. The adsorption procedure is totally fitted with langmuir adsorption isotherm with great correlation coefficient value and furthermore shows monolayer adsorption. The adsorption kinetics is found to pursue pseudo-second- order kinetics. The methodology created by author was exceptionally fruitful in the de-fluoridation of ground water samples. [26]

Kumari et al. (2015) examined defluoridation using shorea robusta. Sal leaf powder demonstrated to be an outstanding adsorbent for defluoridation at optimum $\mathrm{pH}$ of 7.5. The fluoride particle tends to adsorb on the surface of sal leaf powder. The outcome recommends that the pore diffusion is to be considered as significant. The specific uptake of sal leaf powder adsorbent of $0.3 \mathrm{~mm}$ and $1 \mathrm{~mm}$ increases from 0.0195 $\mathrm{mg} / \mathrm{g}$ to $0.158 \mathrm{mg} / \mathrm{g}$ and $0.0135 \mathrm{mg} / \mathrm{g}$ to $0.127 \mathrm{mg} / \mathrm{g}$ individually with the increase in initial concentration of 1.6 $\mathrm{mg} / \mathrm{l}$ to $5 \mathrm{mg} / \mathrm{l}$. SEM combined with EDX characterizations of biosorbents shows the proof for internal circle entanglements and gives a clear image of progress in morphology when fluoride treatment that affirms adsorption of fluoride. [27]

Shyamand et al. (2013) examined the availability of fluoride in sikar aquifer and their expulsion by khimp plant powder. Fluoride concentration in sikar aquifer is impacted by fluoride rich rocks, bicarbonates and so on. Since fluoride is an incredible calcium-chasing particle, it could be precipitated out in possible conditions. The khimp plant (Leptadenia pyrotechnica) has adequate positive calcium particles and collaborates with negatively charged fluoride ions. Various parameters like the impact of $\mathrm{pH}$, agitation time, adsorbent dose and fluoride concentration on adsorption studies have researched. The equilibrium adsorption data was studied for Langmuir and Freundlich isotherms. [28]

Yadav et al. (2014) examined the utilization of aralu (Ailanthus exelsa) stem charcoal for defluoridation process. The aralu stem charcoal is seen as an effective adsorbent for the defluoridation process. The biosorbent was effective in the fluoride removal $10 \mathrm{mg} / \mathrm{l}$ fluoride concentration with about 94\% efficiency. Biosorption equilibrium was accomplished within 180 minutes. The author confirmed that the adsorption was $\mathrm{pH}$ dependent with maximum adsorption occurs at $\mathrm{pH}$ of 5.0 [29]

Mamilwar et al. (2012) examined the fluoride removal starting from the ground water by utilizing babool bark. Examination on the impacts of parameters optimum dose, contact time, $\mathrm{pH}$, temperature and so on was finished by the author. The outcome shows that the babool bark of $5 \mathrm{~g} / \mathrm{l}$ guaranteed the fluoride removal of $77.04 \%$ from $5 \mathrm{mg} / \mathrm{l}$ of fluoride ions concentration at ordinary $\mathrm{pH}$ of 8.0 with contact time of 8 hours. The pseudo-second-order dynamic model fitted well when related with pseudo first-order model. [30]

Anandu Aravind et al. (2015) considered the defluoridation of water utilizing low-cost bio-adsorbents. Prepared moringa oleifera adsorbent shows fluoride removal efficiency of $98.1 \%$ at a contact time of 30 minutes. However, the treated water is so turbid and has some odour issues. The author found that the fluoride expulsion effectiveness increases with the increase in adsorbent dose. The RHAC was recognized as increasingly efficient and conservative for the fluoride removal. The fluoride adsorption efficiency of RHAC is $88.8 \%$ which is obviously high at a contact time of 30 minutes and the turbidity of the treated water is comparatively low and also within the permissible limit. [31]

Telkapalliwar1 et al. (2016) envisioned the fluoride removal from aqueous solution by utilizing inexpensive bark and wood based bio-adsorbents. The fluoride removal has been comprehensively separated into two segments managing the removal of fluoride by bark based and wood based bio adsorbents. The most significant after effects of broad examinations on different factors, for example, $\mathrm{pH}$, contact 
time, temperature and initial fluoride concentration changes the fluoride removal effectiveness of adsorbents alongside the different isotherm models and kinetic models likewise reviewed. [32]

Ravikumar et al. (2014) envisioned the fluoride removal in aqueous system utilizing moringa oleifera seeds. Coagulation with aqueous concentrate of moringa oliefera seed cake powder decreased the fluoride concentration of fluoridated water beneath $1 \mathrm{mg} / \mathrm{l}$ however the turbidity after coagulation was extremely high which was removed by double filtration. At the point when the composite coagulants prepared by including alum and starch with moringa oleifera utilized for coagulation of fluoridated water, the fluoride fixation diminished beneath $1 \mathrm{mg} / \mathrm{l}$ and the turbidity is within the permissible limit. Henceforth the composite coagulant removes fluoride successfully without any increase in the turbidity. [33]

Bhagawati et al. (2012) examined the fluoride removal utilizing the activated carbon prepared from almond shell. Defluoridation utilizing activated carbon preparation from almond shell with $\mathrm{KOH}$ activation in packed bed down flow column was investigated. The impact of different operating parameters, for example, bed height, $\mathrm{pH}$, flow rate, temperature and adsorption limit were investigated. The author focused on chemical characteristics of almond shell, SEM images, and surface area analysis. The fluoride removal from synthetic sample was $63 \%$ and $68 \%$ respectively for CGAC and AGAC for initial fluoride ion concentration of $2 \mathrm{mg} / \mathrm{l}$. The adsorption equilibrium was very much related by BET isotherm model. [34]

Monal Dutta et al. (2012) considered the batch adsorption of fluoride particles onto microwave assisted activated carbon got from acacia auriculiformis scrap wood. The author reasoned that acacia auriculiformis scrap wood adsorbent has better adsorption limit with respect to fluoride in examination with different adsorbents. The adsorptive fluoride removal increased with decrease $\mathrm{pH}$ value and the most extreme fluoride removal happened at a $\mathrm{pH}$ of 4.4. In addition, the fluoride removal increased with increasing contact time, temperature and adsorbent doses yet with decline in particle size. [35]

Sudhanshu Kanaujia et al. (2015) considered the defluoridation in groundwater via carbonized punica granatum carbon CPGC. The author presumed that CPGC has great properties for the sorption of fluoride particles from aqueous solutions. The contact time for fluoride removal was resolved as $75 \mathrm{~min}$. The particle size was a significant parameter which influences the sorption for fluoride on CPGC since the sorption of fluoride particles increases as the particle size decreases. The author reasoned that CPGC can be utilized as an adsorbent for fluoride removal from groundwater where fluoride related issues exist. [36]

Sivasankar et al. (2010) explored the defluoridation from water utilizing enacted and $\mathrm{MnO} 2$-shielded tamarind shell. In the batch method, the elements of fluoride sorption, as for $\mathrm{pH}$,
$[\mathrm{F}] \mathrm{o}$ and sorbent portion was contemplated. The pertinence of pseudo-first order for ATFS and Ritchie-second order for MTFS was recognized. The kinetics data was seen to fit well with Temkin isotherm for ATFS and Langmuir for MTFS. The interaction of co-particles in the defluoridation limit of the sorbent was examined. Column experiments were completed under a constant fluoride concentration of $2 \mathrm{mg} / \mathrm{l}$, flow rate at various bed depths. The adsorption limits of breakthrough and exhaustion points increased with increase in the bed depth of ATFS not at all like MTFS. The representation of the sorbents, ATFS and MTFS was finished utilizing the FTIR, SEM and XRD systems [37]

Sharad Sharma et al. (2014) considered the defluoridation from water utilizing bioadsorbents. The author reasoned that the finely crushed dry neem leaves, grinded pimple leaves, powdered dry ground-nutshells, rice husk and wheat husk an likewise be utilized as bio-sorbents for defluoridation. [38]

Tomar et al. (2014) considered the defluoridation of aqueous media utilizing citrus limonum leaf. The powdered citrus limonum leaf adsorbent for defluoridation was effectively utilized. The fluoride adsorption relies upon $\mathrm{pH}$, adsorbent dose, contact time and fluoride concentration which were optimized. The take-up of fluoride particles is conceivable between $\mathrm{pH}$ of 2 to 8 and most extreme fluoride removal was accomplished at $\mathrm{pH}$ of 2 . The fluoride expulsion rate increased with increase in contact time and adsorbent dose while the rate diminished with increase in fluoride concentration and $\mathrm{pH}$. This investigation reasoned that the powdered citrus limonum leaf material adsorbent successfully used for the fluoride removal in aqueous conditions. [39]

Jain et al. (2013) examined the defluoridation of water utilizing bioadsorbents. The author researched the efficiency of different treated natural adsorbents, for example, neem leaf powder (NL), guava leaf powder (GL), black berry seed powder $(\mathrm{BB})$, neem bark powder $(\mathrm{NB})$, rice husk $(\mathrm{RH})$ and their equivalent extents as blended bio-adsorbents. The analysis has pursued batch process. The adsorption kinetics has been pursued first order rate system for $\mathrm{RH}, \mathrm{GL}$ and NB however BB and NL pursued second order rate mechanism. All adsorbents pursued Freundlich and Langmuir models. The adsorbents utilized were efficient, affordable for removing fluoride from water and removal limit considerably high. Consequently the author reasoned that these alternative adsorbents appears to offer modest and valuable products for efficient fluoride removal from water and furthermore mixed adsorbents give progressively successful and effective outcomes when contrasted with the single one. [40]

\section{CONCLUSION}

A short survey was endeavored to take notice of different low cost adsorbents utilized for the effective defluoridation of water. This survey endeavored to cover a wide scope of adsorbents which have been utilized for the defluoridation process. The efficiency of the adsorbents relies upon $\mathrm{pH}$, adsorbent dose, initial fluoride concentration, surface area, contact time and temperature. The removal of fluoride limits increases by increasing adsorbent dose and diminishing size 
of the adsorbent. From this survey, it was seen that the plant products and waste materials not required any further changes and could be convincing adsorbents for defluoridation purpose. The future research ought to be focused on the improvement of viable and economic adsorbents as far as cost and achievability on the removal of fluoride. The adjustment of adsorbent with appropriate chemical substances or composite adsorbents was likewise commented for the upgrade of efficient defluoridation. From this outline, it is inferred that defluoridation may be possible with waste materials as adsorbents, yet there is a requirement for more examinations to build up waste materials as nonconventional potential source of defluoridation and furthermore to make this method more eco-friendly.

\section{REFERENCES}

[1] A.S. Parlikar, S.S. Mokashi, " A Comparative Study of Defluoridation of Water by Tea Waste and Drumstick as Bioadsorbants", Internationa Journal of Multidisciplinary Research and Development, Vol, 2, July 2015

[2] S. T. Ramesh, R. Gandhimathi, P. V. Nidheesh and M. Taywade, "Batch and Column Operations for the Removal of Fluoride from Aqueous Solution Using Bottom Ash", Environmental Research, Engineering and Management, 2012

[3] S. R. Saranya and N. Anu, “ Comparative Study of Fluoride Removal from Synthetic Wastewater by using Bio-adsorbents", International Journal of Scientific \& Engineering Research, Volume 7, Issue 4, April2016

[4] Aleena R Haneef and Nithya Kurup, “ Comparative Study of Fluoride Removal from Water by Using Muringa Oleifera and Thulsi (Ocimum Sanctum)", International Journal of Scientific \& Engineering Research, Volume 7, Issue 4, April-2016

[5] Sutapa Chakrabarty*, H.P.Sarma, "Defluoridation of contaminated drinkingwater using neem charcoal adsorbent:Kinetics and equilibrium studies", International Journal of ChemTech Research, April-June 2012

[6] Bina Rani, Raaz Maheshwari, Chauhan, A. K., Bhaskar, N. S, "Defluoridation of contaminated water employing brick Powder as an adsorbent", International Journal of Science and Nature, vol. 3(1) 2012 78-82

[7] Renu Singh, Shiv Pratap Raghuvanshi and C.P. Kaushik, "Defluoridation of Drinking Water using Brick Powder as an Adsorbent", Asian Journal of Chemistry, Vol. 20, No. 8 (2008)

[8] Vinish V Nair1, Anandu Aravind2, Dayal Kurian Varghese," Defluoridation of water by composite bed of low-cost bio-adsorbents", International Journal of Advanced Technology in Engineering and Science,Vol.no.4, Issue no. 2, February 2016

[9] G.R.Kiran Kumar, M. Shambavi Kamath and Praveen S Mallapur, "Defluoridation of Water by using Low Cost Activated Carbon Prepared from Lemon Peels", Journal of Basic and Applied Engineering Research, Volume 3, Issue 8; April-June, 2016, pp. 658 660

[10] Dr. D. N. V. Satyanarayana, Smt. M. Sudheera, “ Removal of fluoride Using Brick Powder by Adsorption", International Journal of Research and Analytical Reviews, volume 2, issue 4,Oct. - Dec. 2015.

[11] Nikhil Chavan1, Hema Patel," Removal of Fluoride from Water Using Low Cost Adsorbents", International Journal of Science and Research, Volume 4 Issue 6, June 2015

[12] N.Gandhi, D.Sirisha,K.B. Chandra Shekar and Smita Asthana "Removal Of Fluoride From Water And Waste Water By Using Low Cost dsorbents", International Journal of ChemTech Research, Oct-Dec 2012.

[13] Ranjeeta Soni, Dr. Shikha Modi, “ Removal Of Fluoride From Drinking Water Using Red Mud" International Journal of Scientific \& Technology Research Volume 2, Issue 10, October 2013

[14] R. Bhaumik, N. K. Mondal*, B. Das , P. Roy, K. C. Pal, C. Das, A. Banerjee, and J. K. Datta, "Eggshell Powder as an Adsorbent for Removal of Fluoride from Aqueous Solution: Equilibrium, Kinetic and Thermodynamic Studies, E-Journal of Chemistry, 2012
[15] M. Gourouza, I. Natatou, A. Boos, "Elimination of fluoride ions from an aqueous solution with charred beef shoulder blade bones", J. Mater Environ. Sci. 5 (2) (2014)

[16] Aadesh R. Shrotri, Shubham P.Pandey, "A Review: Studies of Defluoridation of Water by Using Low Cost Adsorbent", International Advanced Research Journal in Science, Engineering and Technology, Vol. 4, Special Issue 3, January 2017

[17] PriyaGoswami, Ashok Sharma, Sarita Sharma, Sanjay Verma, "Defluoridation of Water Using Low CostAdsorbent", International Journal of Chemical Studies 2015; 3(2): 109-112

[18] C. Chakrapani, Ch. Suresh Babu, K.N.K. Vani and K. SomasekharaRao, "Adsorption Kinetics for the Removal of Fluoride from Aqueous Solution by Activated Carbon Adsorbents Derived from the Peels of Selected Citrus Fruits," E-Journal of Chemistry, Vol.7(S1),pp.S419 S427,2010

[19] S. Patil, S. Renukdas and N. Patel, "Defluoridation of Water Using Biosorbents: Kinetic and Thermodynamic Study," International Journal ofResearch in Chemistry and Environment, Vol.3, Issue 1, pp. 125 135,Jan.2013

[20] AashMohammad and C.B. Majumder, "Removal of fluoride from synthetic waste water by using bioadsorbents," International Journal of Research in Engineering and Technology, Vol. 3, Issue 4, pp. 776 785,Apr. 2014

[21] S. Dwivedi, P. Mondal and C. Balomajumder, "Removal of Fluoride using Citrus limetta in batch Reactor: Kinetics and Equilibrium Studies,"Research Journal of Chemical Sciences, Vol. 4, Issue 1, pp. 50-58,Jan.2014

[22] P. S. P. Harikumar, C. Jaseela, TharayilMegha, "Defluoridation of water using biosorbents," Natural Science, Vol. 4 , No. 4, pp. 245-251, April 2012

[23] V. Sudarshan, A. Narsimha, S. Geeta and S. Shankar, "Efficacy of Tuls (Holy Basil) for removal of fluoride in groundwater," International Journal of Recent Scientific Research, Vol. 5, Issue 7, pp. 1236- 1238, 2014.

[24] S. Chakrabarty and H.P. Sarma, "Defluoridation of contaminated drinking water using neem charcoal adsorbent:Kinetics and equilibrium studies," International Journal of ChemTech Research, Vol. 4, No. 2, pp 511-516, April-June 2012

[25] S. Dwivedi, P. Mondal and C. Balomajumder, "Bioadsorption of Fluoride by Ficusreligiosa (Peepal Leaf Powder): Optimization of process Parameters and Equilibrium study," Research Journal of ChemicalSciences,Vol.4,Issue7,pp.52-60,July2014.

[26] M. Suneetha, B. SyamaSundar and K. Ravindhranath, "Studies on fluoride removal from polluted waters using active carbon derived from stems of Abutilon indicum plant," Journal of Chemical Pharmaceutica Research, Vol. 6, No. 10, pp. 574-592, 2014

[27] P. Kumari, N. Kumari and G. Pathak, "Defluoridation of water by a biomass: Shorea Robusta," International Journal of Advanced Technology in Engineering and Science, Vol. 3, Issue 1,pp.1 15,Aug.2015.

[28] R. Shyamand and G.S. Kalwania, "Accumulation of Fluoride in Sikar Aquifer and their Removal by Khimp Plant Powder," Oriental Journal of Chemistry, Vol. 29, No. 3, pp. 1169-1177, 2013.

[29] B. Yadav, A. Garg, P. K. Santra, S. Santra and P. Pathodiya, "Use of Aralu (Ailanthus Exelsa) stem charcoal for defluoridation of drinking water," International Journal of Bioassays, Vol. 3, Issue 3, pp. 1984 $1988,2014$.

[30] B. M. Mamilwar, A. G. Bhole and A. M. Sudame, "Removal of Fluoride From Ground Water By Using Adsorbent," International Journal of Engineering Research and Applications, Vol. 2, Issue 4 pp.334-338,July-August2012.

[31] Anandu Aravind ; Dayal Kurian Varghese ; Arshik K ; Meera S Prasad ; Vinish V Nair, "Defluoridation of Water Using Low-Cost Bioadsorbents: A Comparative Study", International Journal of Engineering Technology Science and Research, Volume2,Issue5,May2015

[32] N. G. Telkapalliwar1, and V. M. Shivankar," Removal of Fluoride From Aqueous Solution By Using Inexpensive Bark And Wood Based Bio-Adsorbents: A Comprehensive Review", IJARIIE, Vol-2 Issue-3 2016.

[33] K. Ravikumar and A. K. Sheeja, "Removal of Fluoride from Aqueous System Using Moringaoleifera Seed Cake and its Composite Coagulants," International Journal of Current Engineering and Technology, Vol. 4, No.1, pp. 1356-1360, Feb. 2014. 
[34] P.B. Bhagawati, C.B. Shivayogimath and M.N. Hiremath, "Column investigation of fluoride on activated carbon prepared from Almond shell,'Journal of Institution of Public Health Engineers, India,Vol. 2012-13.No.2,pp.1-8,July2012.

[35] M. Dutta, T. Ray and J. K. Basu, "Batch adsorption of fluoride ions onto microwave assisted activated carbon derived from Acacia Auriculiformis scrap wood," Archives of Applied Science Research, Vol.4,No.1,pp.536-550,2012.

[36] Sudhanshu Kanaujia, Bharat Singh, Sanjay Kumar Singh, "Removal of Fluoride from Groundwater by Carbonised Punica granatum Carbon", Journal of Geoscience and Environment Protection,2015

[37] V. Sivasankar, T. Ramachandramoorthy and A. Chandramohan, "Fluoride removal from water using activated and $\mathrm{MnO} 2$-coated
Tamarind Fruit(Tamarindusindica) shell: Batch and column studies," J Hazard.Mater., Vol. 177, Issues 1-3, pp. 719-729, May 2010.

[38] Sharad Sharma ,Vibhuti and Aditya Pundhir," Removal of Fluoride from Water Using Bioadsorbents", Current Research in Microbiology andBiotechnology,2014

[39] V. Tomar, "Adsorptive removal of fluoride from aqueous media using Citrus limonum (lemon) leaf,” Microchem. J., Vol. 112, pp. 97-103, Jan. 2014

[40] J. K. Jain and N. Gupta, "Defluoridation of water using bioadsorbents : kinetic study," International Journal of Scientific Research, Vol. 2, Issue12, pp. 171-175, Dec. 2013. 